\title{
A CATARSE NA PEDAGOGIA HISTÓRICO-CRÍTICA
}

\author{
Mario Mariano Ruiz Cardoso ${ }^{1}$ \\ Marcos Francisco Martins ${ }^{2}$
}

\section{RESUMO}

O artigo procura demonstrar, a partir de pesquisa bibliográfica, como a categoria de catarse tem sido apropriada pela Pedagogia Histórico-Crítica. Na primeira parte do texto encontram-se reflexões sobre os fundamentos marxianos e marxistas dessa pedagogia. $\mathrm{Na}$ segunda, são enunciadas as fontes teóricas nas quais a pedagogia em discussão encontra fundamento para a concepção que guarda sobre catarse: Vigotski, Lukács e, principalmente, Gramsci. Na terceira, é apresentada a centralidade da catarse na Pedagogia Histórico-Crítica, a qual a concebe como momento culminante de um processo educativo revolucionário.

Palavras-chave: catarse; educação; fundamentos da educação; Pedagogia Histórico-Crítica.

\section{THE CATHARSIS IN HISTORICAL-CRITICAL PEDAGOGY}

\begin{abstract}
From literature review, the article demonstrates how the category of catharsis has been appropriated by the Historical-Critical Pedagogy. In the first part of the text there are reflections on Marxist foundations of this pedagogy. In the second, presents the theoretical sources that pedagogy in question underlies the conception of catharsis: Vygotsky, Lukacs and especially Gramsci. In the third, the centrality of catharsis is presented in Pedagogy Historical-Critical, which conceives it as a culmination of a revolutionary educational process.
\end{abstract}

Keywords: catharsis; education; foundations of education; Pedagogy Historical-Critical.

\section{Introdução}

A Pedagogia Histórico-Crítica (PHC) é uma das muitas que hoje povoam o cenário educativo nacional. Contudo, guarda como diferencial ser uma das pedagogias contrahegemônicas que se pretende crítica, isto é, que não encara a educação como autônoma em relação à estrutura social, mas como um processo que se articula histórica e dialeticamente com a estrutura e com as relações sociais.

Mesmo originária dos idos de 1980 e com declarada inspiração marxista, sobretudo, em Gramsci, encontra-se a PHC em processo de formulação. Tem sido um grande desafio estabelecer uma metodologia que proponha uma sequência didática para que a PHC possa se consolidar em redes e sistemas de ensino. Em relação ao que se conseguiu avançar até o momento, principalmente por meio do esmero do trabalho de Dermeval Saviani, tem-se claro que a catarse constitui-se como o momento culminante do processo educativo orientado pela PHC, que tem compromisso com a transformação radical da estrutura da sociedade de classes. 
Todavia, são raros os textos que se dedicam a desvelar quais as fontes e o que vem a ser a categoria de catarse para a PHC. Este texto, no espaço limitado que dispõe, propõese a colaborar nesse sentido.

\section{Fundamentos marxianos e marxistas da Pedagogia Histórico-Crítica}

Marx e Engels não tiveram a pretensão de apresentar uma pedagogia inspirada no materialismo histórico-dialético, ou seja, uma orientação à prática educativa inspirada nas trilhas revolucionárias das elaborações que produziram. Contudo, são centrais na obra de Marx e Engels as questões relacionadas ao método de conhecer e de transformar a realidade. O método inaugurado por Marx e Engels é fruto de um longo caminho investigativo e práxico, que resultou em uma orientação teórico-metodológica capaz de fundamentar o conhecimento e as ações transformadoras das diferentes esferas da vida humana, entre elas as que têm como alicerce a formação humana, processo que identifica a educação como dimensão essencialmente humana.

É nesse sentido que Saviani e Duarte assinalaram que "[...] a perspectiva históricoontológica da formação humana se faz presente ao longo de toda a obra de Karl Marx" (2012, p. 20). Nela, pode-se apreender a centralidade do trabalho no que diz respeito ao vínculo de cada indivíduo ao gênero humano. Ao transformar a natureza segundo as próprias necessidades, produzindo objetivações que reconstroem a realidade e modifica a natureza humana, objetiva e subjetivamente, o trabalho constitui-se em um processo humano que se caracteriza por ser orientado por finalidades prévias (antecipação da ação pelo pensamento) e intencionalidades (sentido e significado da ação) resultantes da concretude da vida do sujeito, o que faz com que cada indivíduo e os grupos sociais criem e recriem a realidade vivida, na mesma medida em que a realidade historicamente produzida incide sobre eles como um dos pesos determinantes da forma de ser, de pensar, de agir e de sentir de cada um. Dessa noção resulta uma concepção de processo de formação humana em que educação e sociedade se articulam dialeticamente (cf. MARTINS, 2011), daí ser possível definir “[...] o trabalho educativo [como] o ato de produzir, direta e intencionalmente, em cada indivíduo singular, a humanidade que é produzida histórica e coletivamente pelo conjunto dos homens." (SAVIANI, 2008, p. 13)

Ocorre que, ao se observar o desenvolvimento da humanidade com a consolidação da sociedade capitalista, caracterizada pela relação contraditória entre classes sociais, o trabalho, o resultado do trabalho, o homem e a relação entre os homens têm características afetadas por essa forma de produção e reprodução da vida que articula dialeticamente a dimensão objetiva e subjetiva da realidade vivida, não explicada, portanto, por economicismos e/ou por idealismos. Na perspectiva do materialismo histórico-dialético a compreensão da realidade só pode ser alcançada por meio de um processo de conhecimento cujo critério de verdade e finalidade do conhecimento se identifica com a práxis. "Melhor dizendo, não há verdade fora da práxis, isto é, somente incorporando-se à atividade dos sujeitos é que os conhecimentos se tornam efetivamente verdadeiros." (MARTINS, 2008, p. 157). Saviani, apoiado em Sánchez Vázquez (2011), afirma que a práxis é

[...] uma prática fundamentada teoricamente. Se a teoria desvinculada da prática se configura como contemplação, a prática desvinculada da teoria é puro espontaneísmo. É o fazer pelo fazer. Se o idealismo é aquela concepção que estabelece o primado da teoria sobre a prática, de tal modo que ela se dissolve na teoria, o pragmatismo fará ao contrário, 
estabelecendo o primado da prática. Já a filosofia da práxis, tal como Gramsci chamava o marxismo, é justamente a teoria que está empenhada em articular teoria e prática, unificando-as na práxis. É um movimento prioritariamente prático, mas que se fundamenta teoricamente, alimentase da teoria para esclarecer o sentido, para dar direção à prática. Então a prática tem primado sobre a teoria, na medida em que é originante. A teoria é derivada. Isso significa que a prática é, ao mesmo tempo, fundamento, critério de verdade e finalidade da teoria. (SAVIANI, 2008, p. 141-142)

Ao se investigar, a partir do contexto moderno, o desenvolvimento das forças produtivas e os impactos causados na construção da individualidade e na formação dos grupos sociais, observa-se a alienação e a exploração humana, as quais são típicas da formação econômica e social capitalista e são resultantes do processo de construção da humanidade pelo próprio homem por meio do trabalho. Se é assim, pode-se inferir que há um caminho aberto para elaborar estratégias que se alinhem aos interesses de socializar a riqueza material e não material como forma de ter homens com capacidades e condições de desenvolverem as máximas potencialidades. De modo que instaura uma especificidade da educação no interior das elaborações marxistas.

Ao partir de uma visão histórico-crítica, que leva em consideração a gênese e o desenvolvimento do contexto econômico, social, político e cultural, em articulação com o fenômeno educacional, infere-se ser a educação uma prática social historicamente construída e a sociedade capitalista determinada pela hegemonia da classe que se identifica com o capital, a burguesia. Para ser restabelecida para além do capital, a educação deve ser assumida na luta das classes subalternas pela conquista do que lhe é necessário e de interesse no jogo das contradições que caracterizam o modo de produção e reprodução capitalista, o que abre potencialidades e limites para que a educação esteja aliada a um projeto de construção de uma sociedade sem classes.

É interessante apontar o modo como Saviani, fundamentando no materialismo histórico-dialético, expõe a compreensão sobre a relação entre uma visão crítica sobre a educação, bem como o desafio de elaborar uma pedagogia nessa perspectiva, e o entendimento da formação da subjetividade. Vale lembrar que o marxismo é alvo permanente de críticas pela alegada falta de trato que daria à questão da subjetividade. De acordo com Saviani,

[...] se cada indivíduo sintetiza relações sociais, isto significa que ele só se constitui como homem por meio das relações que estabelece com os outros homens, isto é, só pode tornar-se homem se incorporar em sua própria subjetividade formas de comportamento e ideias criadas pelas gerações anteriores e retrabalhadas por ele e por aqueles que com ele convivem. (SAVIANI, 2004, p. 46)

Chama a atenção o excerto citado sobre a concepção de subjetividade porque Saviani explicita que ela é também um produto histórico, ou seja, só pode ser entendida nas múltiplas relações que estabelece com as condições objetivas e subjetivas vividas por homens concretamente. E relações de tipo dialética, uma vez que

À vista das características da subjetividade humana, evidenciadas pela perspectiva marxiana, o educador, o professor, defronta-se com um educando, com um aluno concreto, e não simplesmente com um aluno empírico. Isto significa que o aluno, isto é, o indivíduo que lhe cabe 
educar, sintetiza em si as relações sociais próprias da sociedade em que vive e em que se dá o processo de sua educação. (Idem, ibidem, p. 47)

A finalidade educativa, portanto, é "[...] tornar os indivíduos contemporâneos à sua própria época" (Idem, ibidem, p. 49), retomando, assim, Gramsci. Dessa maneira, a educação assume a tarefa de colaborar no processo para que os indivíduos e grupos sociais se apropriem da riqueza material e imaterial disponível numa determinada formação econômica e social. Esse movimento de apropriação, que visa a conhecer a realidade para transformá-la, se relaciona com o modo como os homens produzem a própria existência através do trabalho, sendo a educação concebida como "[...] um fenômeno próprio dos seres humanos [o que] significa afirmar que ela é, ao mesmo tempo, uma exigência do e para o processo de trabalho, bem como é, ela própria, um processo de trabalho" (Idem, ibidem, p. 12).

Apoiado em Marx, principalmente no Capítulo VI inédito de O Capital, Saviani diferencia o trabalho não material em dois tipos: a) aquele em que o produto final do processo de trabalho se separa do seu produtor (como, por exemplo, "[...] livros, quadros, todos os produtos artístico que se diferenciam da atividade artística do artista executante" (SAVIANI, 1991, p. 80); b) aquele em que o produto final não se separa do produtor e por isso o consumo se dá no mesmo movimento da produção (Idem, ibidem, p. 81).

É, pois, na segunda modalidade ("o produto não é separável do ato da produção") que Marx situa explicitamente as atividades docentes desenvolvidas nas instituições de ensino

$[\ldots]$

De fato, a atividade educacional tem exatamente esta característica: o produto não é separado do ato de produção. A atividade de ensino, a aula, por exemplo, é alguma coisa que supõe ao mesmo tempo a presença do professor e a presença do aluno. Ou seja, o ato de dar aulas é inseparável da produção desse ato e do consumo desse ato. (Idem, ibidem).

Eis a "natureza da educação" (SAVIANI, 2008, p. 12), o que permite conceituar o

[...] o trabalho educativo [como] o ato de produzir, direta $\mathrm{e}$ intencionalmente, em cada indivíduo singular, a humanidade que é produzida histórica e coletivamente pelo conjunto dos homens. Assim, o objeto da educação diz respeito, de um lado, à identificação dos elementos culturais que precisam ser assimilados pelos indivíduos da espécie humana para que eles se tornem humanos e, de outro lado e concomitantemente, à descoberta das formas mais adequadas para atingir esse objetivo (Idem, ibidem, p. 13)

Percebe-se, então, que a questão da educação mantém, além da relação com o trabalho, uma relação dialética com o conhecimento na perspectiva do materialismo histórico-dialético. Segundo Saviani, a Pedagogia Histórico-Crítica é "[...] uma teoria da educação elaborada diretamente a partir da concepção de conhecimento tal como explicitada por Marx no 'Método da economia política'”. (SAVIANI, 2012a, p. 181).

Disso decorre que a PHC parte da prática social, que em um primeiro momento é tomada pelo educando como algo empírico e caótico, para se alcançar uma prática social como algo concreto e resultante da práxis histórica, ou seja, síntese de múltiplas determinações. $\mathrm{O}$ trabalho educativo a ser realizado para se ter a mudança qualitativa no modo como os homens se inserem na realidade social e econômica, de uma prática social 
tomada como algo empírico, para uma prática social como algo concreto, passa pela identificação dos problemas que essa prática social impõe como elementos que são necessários de serem compreendidos para que se alcance uma inserção mais crítica, para que se alcance uma nova síntese. A partir da identificação dos problemas que os homens necessitam resolver, passa-se à tarefa de propiciar aos educando, pela ação consciente, sistemática e intencional do educador, os instrumentos culturais disponíveis em um determinado contexto histórico e que são indispensáveis para resolução da problemática identificada. O ápice desse processo é quando tais instrumentos, antes tomados como algo externo aos sujeitos, são por eles incorporados, tornando-se elementos fundamentais da ação e da reflexão, proporcionando uma nova visão de mundo, ou seja, uma nova maneira de conhecer e se posicionar na realidade, impulsionando novas ações. A Pedagogia Histórico-Crítica nomeia esse momento como catarse, ou seja,

[...] o momento da expressão elaborada da nova forma de entendimento da prática social a que se ascendeu. [...] Trata-se da efetiva incorporação dos instrumentos culturais, transformados agora em elementos ativos de transformação social. (SAVIANI, 2009, p. 64)

Pode-se afirmar, então, que o conceito de catarse na Pedagogia Histórico-Crítica é central no modo como essa perspectiva pedagógica orienta a prática educativa fundamentada no materialismo histórico-dialético, apontando sempre, conforme assinalou Saviani (Idem, ibidem) para os processos de transformação social, ou seja, para a superação do modo de produção e reprodução capitalista.

\section{As fontes da catarse na PHC: Lukács, Vigotski e Gramsci}

A acepção da catarse na elaboração teórico-metodológica da PHC se assenta no marxismo originário bem como nos aportes de autores marxistas que deram contribuições fundamentais ao entendimento do papel dos processos educativos na construção de uma sociedade comunista. Na obra de Saviani, o conceito de catarse foi elaborado principalmente sob a influência Antonio Gramsci, mas também tem recebido importantes contribuições de Lukács e Vigotski.

Sobre a contribuição desses autores marxistas para a compreensão da catarse na PHC, deve-se destacar o trabalho de Duarte (2010): Arte e Formação humana em Vigotski e Lukács. Ele discute o modo como Lukács e Vigotski abordaram a relação entre "arte e formação humana" (Idem, ibidem, p. 145). Segundo Duarte, a relação dos homens com a produção artística historicamente produzida pelo conjunto da humanidade e a interiorização por meio da catarse na visão de Vigotski faz parte da humanização, ou seja, é uma dimensão essencialmente humana, pois se trata do modo como os homens podem se tornar homens plenos. Nesse sentido, faz parte do processo educativo pelo qual os indivíduos e grupos se formam, apropriando-se da riqueza humana disponível num determinado momento histórico. Ressalte-se que Vigotski está interessado na formação de homens capazes de se inserirem no processo histórico para transformá-lo na direção de uma sociedade comunista. Esse papel social da arte não deve ser confundido com

[...] a utilização da arte na escola com objetivos estranhos e externos à relação propriamente estética entre indivíduo e obra de arte. Ele [Vigotski] critica a educação estética que não promove o que seria o momento culminante da vivência estética, a catarse" (Idem, ibidem, p. 160). 


\section{Duarte explica que}

[...] Vigotski não desconsidera a importância dos efeitos morais da vivência estética, mas enfatiza que a relação do indivíduo com a obra de arte deve ser essencialmente estética, e somente pela mediação dessa relação é que a arte pode exercer um papel formativo. (Idem, ibidem, p. 161)

Também Lukács utiliza a categoria de catarse para aprofundar a reflexão sobre a relação da arte com a formação humana. De acordo com Duarte, "Lukács entende que a catarse não é uma categoria puramente estética; sua origem está na vida dos seres humanos" (Idem, ibidem, p. 147). Segundo esse entendimento, a obra de arte cumpre o papel fundamental de levar os indivíduos a uma vivência dos problemas que encontram na realidade, para além de uma apreensão cotidiana e imediata. $O$ vínculo que arte estabelece com a vida dos homens não se reduz a reproduzir as situações vividas, mas a dar um novo tratamento aos elementos que compõem a realidade e, assim, "[...] superar o imediatismo e o pragmatismo da cotidianidade. A obra de arte é mediadora entre o indivíduo e a vida" (Idem, ibidem), compreensão corroborada por Ferreira (2012) que, sob a orientação de Newton Duarte e apoiado nos escritos de Lukács, disse: “[...] o ensino de literatura na escola deve ter como objetivo principal a desfetichização da realidade humana" (Idem, ibidem, p. 20).

\section{Para Saviani, Lukács e Vigotski}

[...] utilizam o conceito de catarse de uma forma que converge com a de Gramsci, embora o foco não seja o mesmo de Gramsci. Porque em Gramsci o foco é político e pedagógico. Em Lukács o foco é estético e em Vigotski o foco é psicologia da arte, mas o núcleo no qual esse conceito é trabalhado é o marxismo e nesse sentido ele converge com a análise de Gramsci porque por detrás há, aí, o conceito de totalidade. (SAVIANI, 2013b, p. 157)

Lukács, Vigotski e Gramsci, cada um a seu modo, produziram importantes contribuições para que a catarse alcançasse acepção mais universal, dada por autores fundamentados na herança teórico-metodológica de Marx, o que possibilita o aprofundamento do significado da catarse como categoria central na PHC.

É na obra de Saviani que se expressa de maneira explícita a fundamentação gramsciana para a elaboração do conceito de catarse na PHC. Saviani (2013b) explica que antes de iniciar o contato e poder aprofundar o entendimento de Gramsci sobre a estratégia de disputa pela hegemonia pelas classes subalternas e o papel da educação e da catarse nesse processo, o conceito de catarse que ele tinha era ligado ao senso comum, com estreita relação com a vivência artística.

É possível identificar que a catarse a que se refere Saviani, no momento anterior ao contato com a obra de Antonio Gramsci, vinculado ao senso comum, é próxima da acepção da catarse atribuída a Aristóteles (cf. MARTINS, 2011). Lembremos que em a Poética, Aristóteles inclui como um dos efeitos da tragédia, um tratamento dos sentimentos medo e piedade vivenciados pela plateia e há a "purificação desses sentimentos" (ARISTÓTELES, 1991, p. 99). Apesar do entendimento de que esse conceito de catarse em Aristóteles carrega uma relação entre a vivência estética e a questão moral, conforme afirma Saviani, o processo nomeado como catarse que ele remete às experiências de vivência artística e aos contextos de lutas sociais na primeira metade do século XX no Brasil e no período da 
ditadura civil-militar não expressava uma perspectiva de alteração da realidade social, podendo, até mesmo, estar vinculado a um tipo de alienação dos homens em relação aos problemas vivenciados naqueles contextos. A superação desse conceito inicial de catarse é viabilizada pelo modo como Gramsci posiciona o processo catártico dentro da disputa pela hegemonia pelas classes subalternas. A afirmação de Saviani é a seguinte: "[...] aquele conceito do senso comum de fato é superado a partir do meu contato com Gramsci. Aí eu assumo a perspectiva gramsciana que não estava dada no entendimento anterior do conceito de catarse" (SAVIANI, 2013b, p. 149). A incorporação dessa acepção gramsciana se dá nos primeiros escritos sobre a Pedagogia Histórico-Crítica, "[...] que entende que a "catarsis", no seu mais elevado grau (a fase ético-político), deve ser resultado da práxis educativa que assevera o interesse e o compromisso com a transformação das estruturas e superestruturas capitalistas." (MARTINS, 2011, p. 546)

\section{A centralidade da catarse na Pedagogia Histórico-Crítica}

Na perspectiva da PHC, a educação deve alterar de modo radical a qualidade da inserção dos homens na prática social global. O processo educativo deve levar os homens, individual e coletivamente, a modificarem o modo como se relacionam na e com a prática social. Daí a necessidade de propor uma sequência metodológica do processo de ensino.

A construção de uma didática para a PHC é um esforço que vem sendo empreendido por diferentes autores (cf. GASPARIN, 2005; GERALDO, 2009; SANTOS, 2005; MARSIGLIA, 2011), de forma a que possam orientar o ensino das disciplinas que compõem o currículo da escola básica. Saviani, em Escola e democracia (SAVIANI, 2009), indica os seguintes momentos desse processo: prática social inicial, problematização, instrumentalização, catarse e prática social final. A partir dessas orientações gerais, alguns autores têm exposto a preocupação de a PHC orientar a prática educativa em uma perspectiva que articule a unidade entre os fundamentos, os métodos e as finalidades de uma perspectiva pedagógica apoiada no materialismo histórico-dialético.

Ferreira (2012, p. 92) chama a atenção para o fato de que os "passos" da PHC não sejam tomados em si mesmo. Os "passos" devem ser compreendidos como elementos de uma prática educativa capaz de apoiar as classes subalternas na transformação radical da realidade social, ou seja, comprometidos com a construção de uma sociedade sem classes. Com base em Martins (2013), Ferreira aponta o alcance dos "passos" da PHC, os quais são elaborados por Saviani, como "[...] momentos articulados e interdependentes [...]" (Idem, ibidem, p. 289), "[...] não havendo uma correspondência linear entre eles e a organização dos tempos e conteúdos constitutivos da aula em si" (Idem, ibidem). Segundo Saviani,

Em lugar de passos que se ordenam numa sequência cronológica, é mais apropriado falar aí de momentos articulados num mesmo movimento, único e orgânico. O peso e a duração de cada momento obviamente irão variar de acordo com as situações específicas em que se desenvolve a prática pedagógica. (SAVIANI, 2009, p. 67)

Saviani defende o uso de momento ao invés de passos, pois ele diz: "Passos, faz-se um, depois outro, depois outro, enquanto o de momento dá uma ideia de maior articulação" (SAVIANI, 2013b, p. 174). Ao usar o exemplo do problema da utilização de sementes transgênicas, proposta para uma fala sobre PHC e a educação no campo, Saviani chama a atenção para a relação dialética entre os momentos do método da PHC, que podem ocorrer não na necessária ordem que a noção de "passos" implica (SAVIANI, 2013b, p. 177-178). No caso desse exemplo, Saviani discute que para se problematizar essa questão do uso das 
sementes transgênicas "será necessária a apreensão do conceito e significado desse tipo de sementes para se detectar os problemas implicados em sua adoção" (Idem, ibidem, p. 178). Com efeito, para a PHC, nesse caso específico, a instrumentalização não necessariamente ocorre após a problematização, mas há uma articulação recíproca entre esses dois momentos e com a totalidade do método pedagógico histórico-crítico para que o processo educativo alcance a catarse.

A catarse produzida em cada ação educativa se caracteriza como um momento de síntese, tanto do educando como do educador, que ao longo de outras atividades educativas se converte em novas sínteses e vai consolidando a formação do concreto pensado (cf. MARTINS, 2008) na consciência dos sujeitos. A catarse na PHC não poderá ser reduzida a um momento isolado do processo educativo, que ocorre de modo mecânico após a instrumentalização, mas, ao contrário, atingirá a plena expressão na relação dialética que estabelece com as diversas dimensões e momentos da prática educativa, sendo ela própria produtora de uma nova prática social, de novos problemas a serem superados e gerando a necessidade de incorporação de novos conhecimentos que dêem conta das históricas contradições da realidade. A catarse, de acordo com Saviani, “[...] não é uma coisa que vai ocorrer só lá, depois, no final do ano, em novembro quando a disciplina está terminando: 'agora chegou à catarse'" (SAVIANI, 2013b, p. 178).

Desde as primeiras elaborações da PHC, Saviani confere destaque à catarse como ponto culminante do processo pedagógico. Em Escola e democracia, apresenta pela primeira vez o termo catarse como sendo

[...] o momento da expressão elaborada da nova forma de entendimento da prática social a que se ascendeu. Chamemos este quarto passo de catarse, entendida na acepção gramsciana de "elaboração superior da estrutura em superestrutura na consciência dos homens" (GRAMSCI, 1978, p. 53) Trata-se da efetiva incorporação dos instrumentos culturais, transformados agora em elementos ativos de transformação social. (SAVIANI, 2009, p. 64)

A mudança qualitativa de inserção dos homens na realidade que se quer alcançar na prática educativa guiada pela PHC significa a produção de mediações necessárias à transformação social, isto é, do indivíduo, do grupo social em que ele se encontra e do contexto econômico, social, político e cultural vivido. Não é qualquer transformação a pretendida pela PHC, mas a que desencadeia processos de alteração radical e global do modo de produção e reprodução da vida social.

Para tanto, a catarse a ser produzida pela prática educativa requer a incorporação efetiva dos instrumentos culturais pelos indivíduos e grupos sociais, pois são elementos que fazem parte das mediações necessárias à prática social dos homens, de modo a lhes possibilitar condições para a transformação concreta da realidade. A educação é uma das dimensões da luta por essa transformação, e por isso, apesar de ela não alterar de modo direto e imediato a totalidade da vida social, sem as mediações produzidas por ela e, consequentemente, pela catarse gerada pelos processos educativos, não se pode transformar de modo efetivo as condições objetivas e subjetivas da realidade.

Para Saviani, essa perspectiva que não perde de vista as relações entre a prática social e os processos educativos (que também é uma prática social), tem como referência a elaboração de Marx no "método da economia política" (MARX, 1973, p. 228-240) (SAVIANI, 2009, p. 66). O método de Marx "[...] vai do empírico ao concreto pela mediação do abstrato, concluindo que o concreto, sendo unidade da variedade, síntese de múltiplas determinações, é, para o pensamento, um resultado, o ponto de chegada" 
(SAVIANI, 2012b, p. 127). Segundo Saviani, é esse método que conduz Marx na investigação da origem, do desenvolvimento e das tendências de transformação da sociedade burguesa, que serve tanto à produção da ciência, quanto para fundamentar a orientação do processo educativo. Saviani explica que está

[...] querendo dizer que o movimento que vai da síncrise ("a visão caótica do todo") à síntese ("uma rica totalidade de determinações e de relações numerosas") pela mediação da análise ("as abstrações e determinações mais simples") constitui uma orientação segura tanto para o processo de descoberta de novo conhecimentos (o método científico) como para o processo de transmissão-assimilação de conhecimentos (método de ensino). (SAVIANI, 2009, p. 66-67)

No sentido pedagógico dado pela PHC, a prática educativa deve levar o educando a se apropriar da riqueza cultural produzida pela humanidade historicamente e que precisa ser transformada em saber educativo com vistas a produzir catarse. Assim, a catarse como resultado do processo educativo significa a transformação do saber produzido e sistematizado historicamente pela humanidade em concreto pensado na consciência dos homens, a reprodução na consciência do movimento da realidade concreta em movimento, em sua origem e desenvolvimento histórico. É a apropriação da realidade concreta como concreto pensado na mente humana que possibilita uma nova inserção dos homens na realidade social, concebida como produto histórico de homens historicamente produzidos também. É catarse o processo que, por meio dessa incorporação efetiva do patrimônio cultural produzido historicamente, faz o indivíduo mudar qualitativamente a própria visão de mundo, ou seja, a visão de conceber, posicionar-se e agir na realidade. Ao ter em mãos instrumentos culturais sistematizados na forma de ciência, filosofia e arte, que antes eram fatores de desigualdade social, os homens têm a possibilidade de produzir alterações intencionais na prática social. A própria mudança qualitativa na consciência, por meio da apropriação dos elementos culturais pelo processo educativo, é uma mudança qualitativa dessa prática, pois "[...] somos, enquanto agentes sociais, elementos objetivamente constitutivos da prática social [...]" (SAVIANI, 2009, p. 65).

Um exemplo que Saviani utiliza para ilustrar o processo catártico na educação que produz essa transformação no modo como os homens se inserem na realidade concreta é a alfabetização, que possibilita o acesso do educando à cultura letrada como instrumento de ação social (SAVIANI, 2009, p. 67; SAVIANI, 2008, p. 19-22). Saviani indica que é na passagem da condição de "analfabeto para alfabetizado [...] [que] o momento catártico é fixado com nitidez" (SAVIANI, 2009, p. 67). Ele aprofunda a análise desse exemplo para elucidar o efeito que a catarse provoca no processo educativo dos educandos que se apropriam da cultura letrada, de modo sistemático e intencional. $\mathrm{O}$ trabalho do educador na alfabetização utiliza meios necessários para que uma objetivação produzida ao longo da história humana se incorpore à subjetividade do indivíduo. Pela alfabetização o educando coliga os instrumentos necessários de acesso à cultura letrada, que se tornam uma mediação fundamental no seio da prática social. Essa mediação dá novas possibilidades na atuação dos homens na tarefa de transformação da realidade. Sobretudo nos dias atuais, uma vez que a cultura letrada é condição de possibilidade para acessar boa parte do universo cultural disponível em nossa sociedade ${ }^{3}$.

A catarse expressa a passagem do objetivo ao subjetivo, que nas palavras de Saviani assim se manifesta: 
[...] embora metaforicamente por referência ao sentido contido na frase de Gramsci, dá-se, de fato uma "elaboração superior da estrutura em superestrutura na consciência dos homens", isto é, a assimilação subjetiva da estrutura objetiva da língua. E o alfabetizado adquire condições de expressar-se em nível tão elaborado quanto o era capaz o professor no ponto de partida, isto é, ele expressa-se agora não apenas oralmente, mas também por escrito. (Idem, ibidem, p. 67)

Como se pode perceber, a catarse que é produzida na prática educativa também se refere ao modo pelo qual se dá a passagem da desigualdade real e igualdade possível que caracteriza os processos educativos. Põe-se aqui a questão da relação entre escola e democracia numa perspectiva superadora do entendimento liberal desse problema ${ }^{4} \mathrm{e}$ fundamentado na produção de uma democracia real e não formal (Idem, ibidem, p. 69). No caso da alfabetização, a desigualdade real se expressa pelo domínio da leitura e da escrita pelo educador e pelo não domínio dessas ferramentas culturais pelo educando no início do processo educativo; só é instaurada a igualdade concreta entre os dois sujeitos do processo educativo quando, pela catarse, o educando se apropria de modo efetivo da leitura e da escrita, podendo acessar a cultura letrada, antes impossibilitada. Educador e educando, podem ao fim desse processo estabelecer uma relação democrática concreta sob esse ponto de vista (cf. Idem, ibidem, p. 70). De fato, o processo pedagógico "[...] é sempre algum tipo de passagem (de um ponto a outro); uma certa transformação (de algo em outra coisa). É enfim, a própria catarse (elaboração-transformação da estrutura em superestrutura na consciência dos homens)." (Idem, ibidem). É também a passagem do "não-domínio" ao "domínio" pelo educando do saber que interessa ao processo educativo (SAVIANI, 2008, p. 18).

Em Pedagogia Histórico-Crítica: primeiras aproximações, Saviani também utiliza a alfabetização para expor outra dimensão contida na catarse constitutiva do processo educativo: a passagem da necessidade à liberdade, assumindo mais uma vez a acepção gramsciana:

Ora, esse fenômeno está presente também no processo de aprendizagem através do qual se dá a assimilação do saber sistematizado, como o ilustra, de modo eloquente, o exemplo da alfabetização. Também aqui é necessário dominar os mecanismos próprios da linguagem escrita. Também aqui é preciso fixar certos automatismos, incorporá-los, isto é, torná-los parte de nosso organismo, integrá-los em nosso próprio ser. Dominadas as formas básicas, a leitura e a escrita podem fluir com segurança e desenvoltura. À medida que se vai libertando dos aspectos mecânicos, o alfabetizando pode, progressivamente, ir concentrando cada vez mais sua atenção no conteúdo, isto é, no significado daquilo que é lido ou escrito. Note-se que se libertar, aqui, não tem sentido de se livrar, quer dizer, abandonar, deixar de lado os ditos aspectos mecânicos. A libertação só se dá porque tais aspectos foram apropriados, dominados e internalizados, passando, em consequência, a operar no interior de nossa própria estrutura orgânica. Poder-se-ia dizer que o que ocorre, nesse caso, é uma superação no sentido dialético da palavra. Os aspectos mecânico foram negados por incorporação e não por exclusão. Foram superados porque negados enquanto elementos externos e afirmados como elementos internos. (Idem, ibidem, p. 20)

Um ponto importante que Saviani chama a atenção para que a catarse se efetive no caso específico da alfabetização é a necessidade do trabalho educativo contínuo e 
processual, de modo a permitir a incorporação do instrumental cultural de maneira irreversível. De acordo com essa perspectiva, não só o trabalho educativo nos anos iniciais da escolarização é o bastante para que a leitura e a escrita sejam assimiladas pelos educandos, internalizando-se para se tornarem componente orgânico do próprio ser. Tem papel fundamental as atividades educativas que "[...] a criança passará a estudar ciências naturais, história, geografia, aritmética através da linguagem escrita, isto é, lendo e escrevendo de modo sistemático." (Idem, ibidem, p. 21). No caso da alfabetização, pode-se considerar que a catarse ocorre após inúmeras atividades, e até mesmo após alguns anos do primeiro contato que o educando teve com os conteúdos e os procedimentos necessários ao domínio da leitura e da escritura. A superação alcançada em cada atividade educativa, com a apropriação pelos educandos daquilo que está sendo ensinado pelo educador, deve tomar como referência a articulação de um processo mais longo, que representa e se expressa por sucessivas superações, até que o educando possa de fato utilizar os instrumentos da leitura e da escrita com liberdade, e com a "naturalidade" que o impede até de se lembrar de quando não sabia ler e nem escrever.

É nesse sentido que Saviani vincula a concepção de catarse que ele elabora para a PHC à ideia de habitus como "[...] uma disposição permanente, ou, dito de outra forma, quando o objeto de aprendizagem se converte numa espécie de segunda natureza" (Idem, ibidem, p. 20). Saviani assinala:

Adquirir um habitus significa criar uma situação irreversível. Para isso, porém, é preciso ter insistência e persistência; faz-se mister muitas vezes determinados atos até que eles se fixem. Não é, pois, por acaso que a duração da escola primária é fixada em todos os países em pelo menos quatro anos. Isso indica que esse tempo é o mínimo indispensável. Podese chegar a conseguir decifrar a escrita, a reconhecer os códigos em um ano, assim como algumas lições práticas será possível dirigir um automóvel. Mas do mesmo modo que a interrupção, o abandono do volante antes que se complete a aprendizagem determinará sua reversão, também isso ocorre com o aprendizado da leitura. Inversamente, completado o processo, adquirido o habitus, atingida a segunda natureza, a interrupção da atividade, ainda que por longo tempo, não acarreta reversão. Consequentemente, se é possível supor, na escola básica, que a identificação e o reconhecimento dos mecanismos elementares possam ocorrer no primeiro ano, a fixação desses mecanismos supõe uma continuidade que se estende por pelo menos mais três anos. É importante assinalar que essa continuidade se dará através do conjunto do currículo da escola elementar. (Idem, ibidem, p. 21)

Saviani faz referência a Bourdieu e Passeron quando remete ao conceito de habitus para elaborar o conceito de catarse na PHC (SAVIANI, 1996, p. 73). Em La Reproducción, Bourdieu e Passeron utilizam a ideia de habitus para definir o efeito duradouro que os processos educativos produzem ao internalizarem uma determinada cultura no educando através do trabalho pedagógico, "[...] capaz de perpetuar-se uma vez determinada a ação pedagógica [...]” (BOURDIEU \& PASSERON, 1996, p. 72, nossa tradução). Na visão de Saviani, "[...] uma disposição permanente e irreversível que passa a constituir a própria estrutura do sujeito, não lhe sendo possível agir sem que intervenham esses elementos." (SAVIANI, 1996, p. 73). Entretanto, a essa referência que Saviani faz ao conceito de habitus para a explicação da catarse na PHC deve ser somada a indicação da 
[...] articulação com o conceito de "segunda natureza" que é de Gramsci. Então o núcleo gramsciano permanece e não se altera. $\mathrm{O}$ conceito de habitus aparece aí como correlato de segunda natureza. Então, no quadro de Bourdieu, ele ocupa um outro lugar. Aí entro um pouco naquilo que eu costumava dizer para os alunos, para os orientandos, que é o que eu chamo de diferença entre conceito e categoria. (SAVIANI, 2013b, p. 151)

Saviani continua esse trecho citado da entrevista tratando da diferença entre categoria e conceito. Ele diz que "[...] se toda categoria é conceito, nem todo conceito é categoria, porque a categoria é aquele conceito que ocupa um lugar central no contexto de determinada teoria ou área do conhecimento" (Idem, ibidem). Nesse momento, Saviani deixa claro que a fundamentação de Bourdieu e de Gramsci são distintas. Ele diz:

Consequentemente, o conceito de habitus na teoria do Bourdieu assume status de categoria. No marxismo e em Gramsci, o conceito de catarse é que assume o status de categoria. Então o conceito de habitus aí, pode se apresentar e vai expressar um fenômeno correlato ao de catarse, mas ele não tem a amplitude que tem o conceito de catarse em Gramsci. O conceito de catarse como esse movimento que vai do nível econômicocorporativo para o nível ético-político; da estrutura para a superestrutura; do desenvolvimento da práxis social no nível da consciência em si para o nível da consciência para si, todo esse complexo que o conceito de catarse condensa, não está presente no conceito de habitus e na teoria de Bourdieu que utiliza esse conceito com status de categoria. (Idem, ibidem, p. 152-153)

O conceito de segunda natureza, por sua vez, tem referência em Gramsci (SAVIANI, 1996, p. 73). Segundo Saviani,

[...] a expressão segunda natureza parece-[lhe] sugestiva justamente por que nós, que sabemos ler e escrever, tendemos a considerar esses atos como naturais. Nós os praticamos com tamanha naturalidade que sequer conseguimos nos imaginar desprovidos dessas características. Temos dificuldade em nos recordar do período em que éramos analfabetos. As coisas acontecem como se se tratasse de uma habilidade natural e espontânea. E no entanto trata-se de uma habilidade adquirida e, frise-se, não de modo espontâneo. A essa habilidade só se pode chegar por um processo deliberado e sistemático. (SAVIANI, 2009, p. 20)

Ao tratar sobre o estudo do latim na "[...] velha escola média italiana" (GRAMSCI, 2000, p. 45) Gramsci aponta o efeito que esse estudo tinha em produzir nos alunos "[...] uma intuição historicista do mundo e da vida [...]" (Idem, ibidem, p. 48). Essa intuição aprendida através do estudo do latim tornava-se "[...] uma segunda natureza, quase uma espontaneidade [...]" (Idem, ibidem). Para Saviani, essa segunda natureza que informa o conceito que ele elabora de catarse para a PHC é "[...] construída pela educação sobre a base da primeira natureza transmitida por códigos genéticos e pela tradição espontânea." (SAVIANI, 1996, p. 73).

O desafio do educador que deseja se pautar pela PHC é a promoção da catarse através do processo educativo, de forma a produzir no educando uma segunda natureza, algo irreversível (SAVIANI, 2013b, p. 161), “[...] justamente por isso, porque a escrita não é natural, mas, uma vez adquirida - o que é feito normalmente por meio da educação escolar, passa a funcionar como se fosse natural" (Idem, ibidem). No mesmo sentido dessa 
afirmação feita na entrevista, Saviani, no texto Sobre a natureza e especificidade da educação, que compõe o livro Pedagogia Histórico-Crítica, acrescenta:

As coisas acontecem como se se tratasse de uma habilidade natural e espontânea. E no entanto trata-se de uma habilidade adquirida e, frise-se, não de modo espontâneo. A essa habilidade só se pode chegar por um processo deliberado e sistemático. Por aí se pode perceber que o melhor escritor não será, apenas por esse fato, o melhor alfabetizador. Um grande escritor atingiu tal domínio da língua que terá dificuldade em compreender os percalços de um alfabetizando diante de obstáculos que, para ele, inexistem ou, quando muito, não passam de brincadeira de criança. Para que ele se converta num bom alfabetizador, será necessário aliar ao domínio da língua o domínio do processo pedagógico indispensável para se passar da condição de analfabeto à condição de alfabetizado. Com efeito, sendo um processo deliberado e sistemático, ele deverá ser organizado. O currículo deverá traduzir essa organização dispondo o tempo, os agentes e os instrumentos necessários para que os esforços do alfabetizando sejam coroados. (SAVIANI, 2008, p. 20-21)

Nesse sentido, a catarse na PHC se vincula à capacidade de o processo educativo transformar de modo radical os indivíduos e grupos que dele participam. Essa transformação, que pela educação pode ser produzida de modo intencional e sistemático, é fator fundamental para uma perspectiva de alteração da realidade global. Se a realidade atualmente foi produzida por homens e pode ser alterada por homens, é necessário que os homens tenham condições e desejem produzir essa transformação. Assim, tornam-se indispensáveis processos educativos que produzam esses homens e suas vontades, por meio de uma prática educativa que resulte em catarse, elevando os instrumentos culturais produzidos pela humanidade em instrumentos dos próprios homens transformados, elementos da própria natureza desses homens, especificamente, uma segunda natureza produzida de modo consciente.

O que pode estear a prática educativa a alcançar o ponto culminante, ou seja, a incorporação por parte dos educandos dos saberes historicamente sistematizados na forma de ciência, filosofia e arte, tornados ferramentas da própria vida, da própria prática social? Para dar encaminhamento a essa resposta, entende-se necessário explorar o conceito de "clássico" e a noção da história como eixo articulador dos processos educativos, conforme elaborados por Saviani sob a influência da escrita de Gramsci nos Cadernos do Cárcere.

Saviani e Duarte indicam "[...] que o termo 'clássico' não coincide com o tradicional e também não se opõe ao moderno. [...]" (SAVIANI e DUARTE, 2012, p. 31) e continuam:

[...] clássico é aquilo que resistiu ao tempo, tendo uma validade que extrapola o momento em que foi formulado. Define-se, pois, pelas noções de permanência e referência. Uma vez que, mesmo nascendo em determinadas conjunturas históricas, capta questões nucleares que dizem respeito à própria identidade do homem como um ser que se desenvolve historicamente, o clássico permanece como referência para as gerações seguintes que se empenham em apropriar-se das objetivações humanas produzidas ao longo do tempo. (Idem, ibidem)

A noção de clássico pode apoiar os educadores na produção da catarse, uma vez que ela aponta para os problemas nucleares vividos pela humanidade e expressos na 
produção cultural a ser incorporada pelos educandos. Essa noção poderá ser um parâmetro para que o educador avalie quais conteúdos e quais os meios farão parte do trabalho educativo que ele desenvolverá, uma vez que toda atividade educativa significa escolhas em meio à riqueza cultural produzida pela humanidade ao longo dos tempos. Entretanto, se o que se quer é "[...] produzir, direta e intencionalmente, em cada indivíduo singular, a humanidade que é produzida histórica e coletivamente pelo conjunto dos homens" (SAVIANI, 2008, p. 13), faz-se necessário identificar os elementos culturais que são capazes de sintetizar essa rica experiência humana e que, quando apreendidos pelos educandos, possam servir para alterarem as inserções na prática social vivida. Nesse sentido, parece que a noção de clássico é um instrumento efetivo para subsidiar o educador na tarefa de "[...] identificação dos elementos naturais e culturais necessários à constituição da humanidade em cada ser humano e a descoberta das formas adequadas para atingir esse objetivo" (SAVIANI, 2008, p. 22). No campo da filosofia, Duarte e Saviani exemplificam essa situação afirmando que

[...] o estudo crítico dos grandes filósofos, isto é, dos clássicos da filosofia, é uma via de acesso privilegiada à compreensão da problemática humana, o que tem grande valor educativo, já que a educação não é outra coisa senão o processo por meio do qual se constitui em cada indivíduo a universalidade própria do gênero humano. (SAVIANI \& DUARTE, 2012, p. 31)

Saviani chama a atenção para que o estudo dos clássicos tenha um caráter crítico. Com efeito, não basta aos educandos entrarem em contato com os clássicos de cada conteúdo educativo, mas essa atividade ganha relevância para uma perspectiva crítica em educação quando articulada à totalidade da vida social. A noção de clássico na Pedagogia Histórico-Crítica está articulada à tarefa de buscar respostas na rica experiência histórica humana para os problemas (entendido como uma necessidade vital) identificados na prática social de educadores e educandos. Se se tomar a prática social como algo concreto e síntese de múltiplas determinações, e mergulhar na historicidade que a caracteriza, podese identificar os nexos e processos contraditórios que a formaram. Nesse sentido, os clássicos possuem papel relevante, pois proporcionam a busca por essa historicidade, bem como dos problemas mais relevantes que os homens enfrentaram até alcançarem o estágio de desenvolvimento em que se encontram. O exame crítico dos clássicos através do processo educativo serve para revelar a humanidade dessas produções, expressando os dilemas e contradições que constituem a história humana. Nessa perspectiva, o senso comum, que orienta o modo como os educandos conhecem e atuam na prática social, é enriquecido por novas determinações advindas do acesso ao saber elaborado. $\mathrm{O}$ bom senso, núcleo sadio do senso comum que deve ser trabalhado para se alçar a uma visão de mundo mais crítica da realidade, por meio do processo educativo que considera a noção de clássico, é superado por incorporação, não sendo descartado, mas transformando-se em um tipo de consciência capaz de orientar a ação transformadora da realidade.

Motivado pela reflexão de Gramsci contida nas passagens dos escritos carcerários que tratam sobre a importância do latim na velha escola tradicional italiana e a função historicista que o estudo dessa língua desenvolveu nos alunos (GRAMSCI, 2000, p. 4849), Saviani declara o seguinte:

Desde a primeira vez em que li essas passagens, nos idos da década de 70 do século passado, sempre me perguntava sobre a ou as matérias que pudessem desempenhar numa nova escola adequada aos tempos atuais 
papel equivalente àquele desempenhado pelo latim e pelo grego na velha escola. E uma ideia começou a tomar forma em meu espírito. Essa ideia é a de que a história seria exatamente essa matéria que ocuparia o lugar central no novo princípio educativo da escola do nosso tempo: uma escola unitária porque guiada pelo mesmo princípio, o da radical historicidade do homem e organizada em torno do mesmo conteúdo, a própria história dos homens, identificado como caminho comum para formar indivíduos plenamente desenvolvidos. Com efeito, que outra forma poderíamos encontrar de "produzir, em cada indivíduo singular, a humanidade que é produzida histórica e coletivamente pelo conjunto dos homens" (SAVIANI, 2003, p. 13) senão fazendo-os mergulhar na própria história e, aplicando o critério de "clássico", permitir-lhes vivenciar os momentos mais significativos dessa verdadeira aventura temporal humana? (SAVIANI, 2012c, p. 129)

A radical historicidade do homem buscada na própria história da humanidade como conteúdo central dos processos educativos parece indicar uma maneira de compreender a produção de processos catárticos por meio da educação. É a apreensão da realidade concreta pelos homens, concretude que é explicitada na história humana através da identificação das múltiplas e ricas determinações da produção dessa realidade, que determina a produção de uma catarse pelos processos educativos. A catarse, então, pode significar a passagem de uma visão a-histórica a uma visão histórica da realidade humana, sendo possível através da historicização dos conteúdos culturais que serão apropriados pelos educandos, o que é "fundamental" (SAVIANI, 2011, p. 137).

Assim, a catarse promovida pelo processo educativo aponta para um tipo de formação humana que produz sujeitos cientes do caminho percorrido pela humanidade, neles incorporando a "[...] humanidade produzida historicamente e coletivamente pelos conjuntos dos homens" (SAVIANI, 2010, p. 422), o que os possibilita conceber novas formas de sociabilidade, isto é, novas relações de produção e reprodução da vida social. É nesse sentido que Saviani afirma que a '[...] 'pedagogia histórico-crítica' tem Gramsci como uma de suas principais referências, tanto que elegeu a categoria gramsciana da 'catarse' como o momento culminante do processo pedagógico." (SAVIANI, 2013a, p. 68).

Saviani conclui,

Pela catarse o processo educativo atinge seu ápice, propiciando aos educandos atingir uma concepção superior, liberta de toda magia e bruxaria. Pela catarse dá-se a passagem do nível puramente econômico ao momento ético-político. Igualmente, pela catarse dá-se a elaboração superior da estrutura em superestrutura na consciência dos homens, ou seja, ocorre a assimilação subjetiva das condições objetivas, permitindo a passagem da condição de classe-em-si para a condição de classe-para-si. É, enfim, pela catarse que tudo aquilo que era objeto de aprendizagem se incorpora no próprio modo de ser dos homens, operando uma espécie de segunda natureza que transforma qualitativamente sua vida integralmente, isto é, no plano das concepções e no plano da ação. (SAVIANI, 2013a, p. 74)

Por fim, cabe ressaltar que a catarse que se deseja alcançar no processo educativo orientado pela PHC, conforme assinalou Saviani, transforma as concepções e o plano de ação dos educandos. Está explícita a intencionalidade desse processo, qual seja uma catarse que promova a passagem de homens parciais para homens plenos de sua humanidade. 


\section{Apontamentos conclusivos}

A Pedagogia Histórico-Crítica surgiu no contexto brasileiro enriquecendo o debate pedagógico travado na década de 1980. Em meio às correntes pedagógicas contra hegemônicas, que recolocavam a importância da dimensão educativa no processo de transformação social, a PHC se fortaleceu como uma pedagogia de inspiração marxista e desenvolveu um método pedagógico fundamentado no método da economia política e da práxis revolucionária expostas por Marx para conhecer e transformar a sociedade burguesa. Marcadamente marxista, a PHC incorporou a categoria de catarse, de inspiração gramsciana, como momento culminante do processo educativo. Assim interpretada a PHC, há dois destaques a serem feitos sobre ela neste momento final deste artigo.

O primeiro refere-se ao trabalho originário de Saviani como o principal formulador da PHC. Mesmo reconhecendo a contribuição de outros autores, Saviani parte da referência direta a Gramsci para produzir uma pedagogia crítica e a categoria de catarse possibilita-lhe essa criticidade, o que significa "[...] compreender a educação remetendo-a sempre a seus condicionantes objetivos, isto é, aos determinantes sociais, vale dizer, à estrutura sócio-econômica que condiciona a forma de manifestação do fenômeno educativo." (SAVIANI, 2009, p. 9). Dessa maneira, Saviani tem avançado na produção de uma pedagogia que reconhece, no processo educativo, a desigualdade como ponto de partida, mas que almeja a igualdade como ponto de chegada, possibilitada pela catarse, que se manifesta, também, nos sujeitos educativos como a passagem da necessidade à liberdade.

O segundo destaque a fazer é que, originário das formulações de outros importantes marxistas, para além de Gramsci, Vigotski e Lukács, a categoria de catarse tem sido apropriada por aqueles que estão formulando a PHC porque ela exige a articulação do saber elaborado com as lutas sociais, especialmente com as que visam a alterar a atual configuração do metabolismo social do capitalismo contemporâneo. Isso retoma a escola como espaço não apenas de reprodução da vida social, mas também de mediação do processo de transformação social. Nesse sentido, a categoria de catarse, que é central na PHC, a remete para o campo das pedagogias revolucionárias, o que é coerente com o fundamento que a orienta, o materialismo histórico-dialético.

\section{Referências}

ARISTÓTELES. Ética a Nicômaco; Poética / Aristóteles; seleção de textos de José Américo Motta Pessanha. - 4. ed. — São Paulo : Nova Cultural, 1991. — (Os pensadores; v. 2)

BOURDIEU, Pierre; PASSERON, Jean-Claude. La Reproducción: elementos para una teoria del sistema de enseñanza. México DF: Distribuciones Fontamara, 1996.

DUARTE, Newton. Arte e Formação humana em Vigotski e Lukács. In: DUARTE, Newton; DELLA FONTE, Sandra Soares. Arte, conhecimento e paixão na formação humana: sete ensaios de pedagogia histórico-crítica. Campinas, SP: Autores Associados, 2010. (Coleção educação contemporânea)

FERREIRA, Natália Botura de Paula. A catarse estética e a pedagogia histórico-crítica: contribuições para o ensino de Literatura. 2012. 170f. Tese (Doutorado em Educação Escolar) - Faculdade de Ciências e Letras, Campus Araraquara. Universidade Estadual Paulista, Araraquara. 
GASPARIN, João Luiz. Uma didática para a Pedagogia Histórico-Crítica. $3^{\text {a }}$ ed. rev. Campinas, SP: Autores Associados, 2005. (Coleção educação contemporânea)

GERALDO, Antonio Carlos Hidalgo. Didática de ciências naturais na perspectiva histórico-crítica. Campinas, SP: Autores Associados, 2009. (Coleção formação de professores).

GRAMSCI, Antonio. Cadernos do Cárcere. Volume II - Os intelectuais; o princípio educativo; jornalismo. Edição e tradução de Carlos Nelson Coutinho; co-edição, Luiz Sérgio Henriques e Marco Aurélio Nogueira. Rio de Janeiro: Civilização Brasileira, 2000.

MARSIGLIA, Ana Carolina Galvão. A prática pedagógica histórico-crítica na educação infantil e ensino fundamental. Campinas, SP: Autores Associados, 2011. (Coleção Educação contemporânea)

MARTINS, Ligia Márcia. O desenvolvimento do psiquismo e a educação escolar: contribuições à luz da psicologia histórico cultural e da pedagogia histórico-crítica. Campinas, SP: Autores Associados, 2013.

MARTINS, Marcos Francisco. Marx, Gramsci e o conhecimento: ruptura ou continuidade? Campinas, SP: Autores Associados; Americana, SP: UNISAL - Centro Universitário Salesiano de São Paulo, 2008. (Coleção educação contemporânea)

Práxis e "catarsis" como referências avaliativas das ações educacionais das ONG's, dos sindicatos e dos partidos políticos. Avaliação, Campinas, v. 16, n. 3, p. 533 558, nov. 2011.

e VARANI, Adriana. Professor e pesquisador: considerações sobre a problemática relação entre ensino e pesquisa. In: Rev. Diálogo Educ., Curitiba, v. 12, n. 37, p. 647-680, set./dez. 2012. Disponível em http://www2.pucpr.br/reol/index.php/dialogo?dd99=pdf\&dd1=7196. Acesso em 06 de novembro de 2013.

MARX, Karl. Contribuição para a crítica da economia política. Lisboa: Estampa, 1973.

SÁNCHEZ VÁZQUEZ, Adolfo. Filosofia da Práxis. $2^{\text {a }}$ ed. Buenos Aires: Consejo Latinoamericano de Ciencias Sociales - Clacso: São Paulo: Expressão Popular, Brasil, 2011.

SANTOS, César Sátiro dos. Ensino de Ciências: abordagem histórico-crítica. Campinas, SP: Armazém do Ipê (Autores Associados), 2005.

SAVIANI, Dermeval. Ensino Público e algumas falas sobre universidade. 5. ed. São Paulo: Cortez: Autores Associados, 1991. (Coleção polêmicas de nosso tempo; v. 10)

Paulo, Jan./Apr, 1996.

Florestan Fernandes e a educação. Estudos Avançados. Vol. 10, n 26, São

Perspectiva Marxiana do Problema Subjetividade-Intersubjetividade. In: DUARTE, Newton (org). Crítica ao fetichismo da individualidade. Campinas, SP: Autores Associados, 2004.

Pedagogia histórico-crítica: primeiras aproximações. 10 ed. rev. Campinas, SP: Autores Associados, 2008. (Coleção educação contemporânea) 
Escola e Democracia: teorias da educação, curvatura da vara, onze teses sobre educação política. $41^{\mathrm{a}}$ edição - Campinas, SP: Autores Associados, 2009. (Coleção Polêmicas do nosso tempo, v. 5)

Histórias das ideias pedagógicas no Brasil. 3. ed. rev. Campinas, SP: Autores Associados, 2010. (Coleção memórias da educação)

. Educação em diálogo. Campinas, SP: Autores Associados, 2011. (Coleção Memórias da Educação)

História, trabalho e educação: comentários sobre controvérsias internas ao campo marxista. In: SAVIANI, Dermeval; DUARTE, Newton (orgs). Pedagogia Histórico-Crítica e luta de classes na educação escolar. Campinas, SP: Autores Associados, 2012a. (Coleção polêmicas do nosso tempo).

. Debate sobre educação, formação humana e ontologia a partir da questão do método dialético. In: SAVIANI, Dermeval; DUARTE, Newton (orgs). Pedagogia Histórico-Crítica e luta de classes na educação escolar. Campinas, SP: Autores Associados, 2012b. (Coleção polêmicas do nosso tempo).

A pedagogia no Brasil: história e teoria. $2^{\mathrm{a}}$ ed. Campinas, SP: Autores Associados, 2012c. (Coleção memórias da educação)

. Aberturas para a história da educação: do debate teórico-metodológico no campo da história ao debate sobre a construção do sistema nacional de educação no Brasil. Campinas, SP: Autores Associados, 2013a.

Entrevista concedida a Mario Mariano Ruiz Cardoso e a Marcos Francisco Martins. Campinas-SP, Faculdade de Educação da Unicamp, em 18 de novembro de $2013 b$.

e Duarte, Newton. A formação humana na perspectiva histórico-ontológica. In: SAVIANI, Dermeval; DUARTE, Newton (orgs). Pedagogia Histórico-Crítica e luta de classes na educação escolar. Campinas, SP: Autores Associados, 2012. (Coleção polêmicas do nosso tempo).

\section{Notas}

\footnotetext{
${ }^{1}$ Professor Auxiliar e Substituto da Universidade Federal dos Vales do Jequitinhonha e Mucuri (UFVJM) campus JK, onde leciona disciplinas nos Cursos de Pedagogia e Bacharel Interdisciplinar em Humanidades. Possui graduação em Licenciatura em Ciências Biológicas pela Universidade Estadual de Campinas (UNICAMP) e Mestrado em Educação pela Universidade Federal de São Carlos (UFSCar), campus Sorocaba. É integrante do Grupo de Pesquisa Teorias e Fundamentos da Educação da UFSCar (GPTeFE), campus Sorocaba e também do Grupo de Estudos e Pesquisas Marxistas da UFVJM (GEPEMARX/UFVJM). E-mail: mariobiologo@gmail.com

${ }^{2}$ Professor Adjunto da Universidade Federal de São Carlos (UFSCar) - campus Sorocaba, onde coordena o Programa de Mestrado em Educação e lidera o GPTeFE (Grupo de Pesquisa Teorias e Fundamentos da Educação). Bolsista de Produtividade em Pesquisa do Conselho Nacional de Desenvolvimento Científico e Tecnológico (CNPq), graduado em Filosofia (PUC-Campinas), com mestrado e doutorado em Filosofia e História da Educação (FE-Unicamp).E-mail:marcosfranciscomartins@gmail.com

${ }^{3}$ Tal importância pode ser exemplificada pelos esforços de governos na América Latina identificados com uma perspectiva de "esquerda" que demonstram uma valorização da cultura ligada aos povos indígenas e afrodescendentes na erradicação do analfabetismo como fator importante para a construção de alterações
} 
econômicas, sociais e culturais que superem uma histórica submissão dessas nações à submissão ao imperialismo estadunidense

${ }^{4} \mathrm{O}$ entendimento liberal da questão da relação entre escola e democracia que se pontuou nesse trecho referese à compreensão que declara que, assim como na sociedade em geral, no caso específico da escola, todos são iguais. Do ponto de vista formal e legal, essa é uma afirmação que pode ser entendida com alguma correspondência com a realidade. Mas a aproximação da concretude da educação escolar possibilita ver que as classes subalternas nas sociedades capitalistas não têm o acesso garantido ao saber sistematizado, sendo que o não domínio desse saber elaborado acaba, de modo real e concreto, sendo um fator de desigualdade, não tendo validade, nesse sentido, a afirmação que todos são iguais, como asseveram os liberais.

Recebido: $\quad$ março/14 Aprovado: junho/14 